\title{
Development and evaluation of a fluorogenic 5'-nuclease assay to identify Marburg virus
}

\author{
T. R. Gibb,* D. A. Norwood Jr., N. Woollen and E. A. Henchal \\ Diagnostic Systems Division, United States Army Medical Research Institute of \\ Infectious Diseases, 1425 Porter Street, Fort Detrick, Maryland 21702-5011, USA
}

(Received 6 April 2001, Accepted 14 May 2001)

\begin{abstract}
The ability to rapidly recognize Marburg virus infections is critical to quickly institute proper barrier nursing precautions and limit further spread of the disease. A rapid, sensitive, and specific laboratory diagnostic test is necessary to confirm outbreaks of Marburg virus and to distinguish it from other diseases that can present with similar clinical symptoms.

A one-tube reverse transcriptase-polymerase chain reaction (RT-PCR) assay for the identification of Marburg virus was developed and evaluated using the ABI PRISM ${ }^{\mathrm{TM}} 7700$ Sequence Detection System and TaqMan ${ }^{\circledR}$ chemistry. The sensitivity and specificity of the newly designed primer/probe set (MBGGP3) was evaluated. MBGGP3 was equivalent to or 10-100-fold more sensitive than previously designed primer sets as determined by limit of detection experiments. In addition, the MBGGP3 assay was able to detect all strains of Marburg virus tested, but gave negative results with other haemorrhagic fever and genetically related viruses. The results of this study indicate that the MBGGP3 primer/probe set is both sensitive and specific. In addition, this assay is compatible with emerging rapid nucleic acid analysis platforms and therefore may prove to be a useful diagnostic tool for the control and management of future outbreaks.
\end{abstract}

(C) 2001 Academic Press

KEYWORDS: Marburg virus, filoviruses, $\operatorname{TaqMan}^{\circledR}$, RT-PCR, diagnostic, fluorogenic 5'-nuclease assay.

\section{INTRODUCTION}

Marburg virus is a single, non-segmented, negativestranded RNA virus belonging to the family Filoviridae. It is one of two members of the Filoviridae (Ebola virus and Marburg virus) family, which is responsible for sporadic epidemics of haemorrhagic fever in human and non-human primates.

Infection with Marburg virus results in a rapid disease progression with mortality rates of approximately $30 \%$. The main route of filovirus transmission is contact with infected body fluids, and can occur through improper needle hygiene, direct contact with infected tissue or fluid samples, and close contact with infected patients. ${ }^{1-3}$ Consequently, those at greatest risk for contracting the disease are health-care providers and families, which in the rural African communities may be the primary care providers for sick patients. Because of the mode of transmission, high fatality rates, and the need to institute proper barrier nursing precautions and public health measures, it is essential to establish a diagnosis early in the course of disease. ${ }^{4}$ In regions of Africa where numerous diseases can present with similar clinical syndromes (Lassa fever, Shigella dysentery and malaria), the diagnosis of filoviral infections can present a challenge. During an outbreak the ability to establish a rapid diagnosis may help save the lives

\footnotetext{
* Author to whom all correspondence should be addressed at: CPT Tammy Gibb DSD, USAMRIID 1425 Porter Street, Fort Detrick,
} MD 21702-5011. 301-619-7193; Fax: 301-619-2492. 
of patients presenting with treatable diseases such as Shigella dysentery, and malaria. In these instances, proper triage of patients depends heavily on a rapid and accurate diagnosis.

Assays currently available to diagnose Marburg virus infections include virus culture, transmission electron microscopy (TEM), immunohistochemistry, antigen-detection enzyme-linked immunosorbent assays (ELISAs), antibody-detection ELISAs, and a conventional reverse-transcriptase polymerase chain reaction (RT-PCR). ${ }^{5}$ Each method has both advantages and disadvantages, however, to date there are few assays available that are capable of providing a sensitive, specific, and rapid diagnosis under field conditions. Virus culture is sensitive but must be performed in a biological safety level-4 (BSL-4) laboratory. TEM is a rapid technique $(<3 \mathrm{~h})$ but is usually only available in well-equipped research facilities. ${ }^{6}$ Both virus culture and TEM are routinely performed by reference laboratories. Antibody-detection ELISAs are often unreliable because patients with symptomatic filoviral infections often do not mount a detectable humoral response before death. ${ }^{7,8}$ Antigendetection ELISAs are adequate for detecting Marburg virus infections during the acute stages of infection, however, special precautions must be taken when handling infectious samples. To date, the most rapid and potentially deployable assay that has good clinical sensitivity is based on conventional RT-PCR.

Conventional RT-PCR is a more sensitive method than antigen-detection ELISAs, and has the advantage of rendering samples non-infectious before use. However, current RT-PCR assays are not capable of detecting all known strains of Marburg virus, and they are not compatible with emerging rapid nucleic-acid analysis systems. ${ }^{9}$ Newly designed rapid nucleic-acid analysis systems use a fluorogenic probe-based assay to monitor the accumulation of PCR product in real time. ${ }^{10}$ Adding a probe that recognizes a complementary DNA sequence between the two primers provides an increased level of specificity to the PCR reaction. With these assays it is possible to detect a positive sample in $1 \mathrm{~h}$ or less. Fluorogenic probes are not incorporated into the design of conventional RTPCR assays, therefore these assays cannot be monitored on real-time nucleic-acid analysis systems. Instead, following RT-PCR, which is routinely performed as two separate steps (an RT step and PCR step), samples must be analysed by gel electrophoresis. The total assay time for conventional RT-PCR, including data analysis by gel electrophoresis, can take 3-4 h. In this study we report the development of a fluorogenic probe-based, one-step RT-PCR assay, based on the dual RT and DNA polymerase activities of the recombinant, thermostable Thermus thermophilus
(rTth) enzyme (Applied Biosystems, Foster City, CA, USA). This assay is based on the $5^{\prime}$-nuclease assay which exploits the $5^{\prime}$ nuclease activity of $r$ Tth polymerase to cleave a non-extendable, dual-labelled fluorogenic probe that is annealed to the target sequence during amplification. ${ }^{11-13}$

The purpose of this study was to demonstrate a highly sensitive, specific, and rapid assay that is compatible with emerging rapid nucleic-acid analysis platforms. The MBGGP3 RT-PCR assay utilizes a fluorogenic 5'-labelled probe capable of recognizing all tested strains of Marburg virus. Samples are rendered non-infectious prior to use and the risk of crosscontamination between samples is minimized because there is only one set of reagent-addition steps, and no handling of samples after PCR. The development of this assay provides a new diagnostic tool for identification of Marburg infections that may be useful for future outbreak detection and management.

\section{MATERIALS AND METHODS}

\section{Virus growth, purification, and titres}

Ebola, Marburg, and Lassa virus strains were propagated in Vero E6 cells. Crimean-Congo haemorrhagic fever (CCHF) and measles (Edmonston strain) viruses were propagated in Vero cells. Vesicular stomatitis virus (VSV) was propagated in baby hamster kidney (BHK) cells. Upon visualization of $60-70 \%$ cytopathic effects (CPE), supernatant was harvested and clarified by centrifugation. For Ebola, Marburg, and measles virus purification, the supernatant was clarified in a Sorvall centrifuge at $1500 \times$ g for $15 \mathrm{~min}$. Polyethylene glycol [PEG, average molecular weight (MW) 8000] and $\mathrm{NaCl}$ was added to the supernatant to a final concentration of $7.5 \% \mathrm{w} / \mathrm{v}$ and $0.5 \mathrm{M}$, respectively. Virus was allowed to precipitate for $4 \mathrm{~h}$ at $4^{\circ} \mathrm{C}$. Precipitated virus was pelleted at $10000 \times \boldsymbol{g}$ for $30 \mathrm{~min}$ in a Sorvall centrifuge and suspended in $5 \mathrm{ml}$ of TNE (10 mM Tris- $\mathrm{HCl}, \mathrm{pH} 8 \cdot 0,100 \mathrm{mM} \mathrm{NaCl}$, and $1 \mathrm{mM}$ EDTA, pH 8.0). Suspended virus was then concentrated by ultracentrifugation in a SW41 rotor at $38000 \mathrm{rpm}$ through a $20-60 \%(\mathrm{w} / \mathrm{w})$ sucrose gradient in TNE. ${ }^{14}$ For CCHF virus, the supernatant material was precipitated with $8 \%(\mathrm{w} / \mathrm{v})$ PEG containing $2 \cdot 3 \%$ $(\mathrm{w} / \mathrm{v}) \mathrm{NaCl}$ for $3 \mathrm{~h}$ at $4{ }^{\circ} \mathrm{C}$. The precipitate was pelleted, resuspended in TNE, and overlayed onto a 15-65\% $(\mathrm{w} / \mathrm{w})$ sucrose gradient in TNE. The gradients were centrifuged in a SW41 rotor at $40000 \mathrm{rpm}$ for $1.5 \mathrm{~h}$ at $4{ }^{\circ} \mathrm{C}$. Direct analysis of $1 \mathrm{ml}$ fractions of the gradient, by SDS polyacrylamide gel electrophoresis, as described previously, ${ }^{15}$ were performed. For Lassa virus 
Table 1. Marburg primer sets

\begin{tabular}{lcccc}
\hline Primer set & Target gene & Amplicon length (bp) & TaqMan $^{\circledR}$ assay & Reference \\
\hline REM2/REM3* & NP & 223 & No & (Not published**) $^{* *}$ (Sanchez et al. $\left.{ }^{9}\right)$ \\
FILOA/FILOB* & L & 419 & No & (This study) \\
MBGGP3 & GP & 143 & Yes & (T) \\
\hline
\end{tabular}

Key: ${ }^{*}=$ Previously published primer sets. ${ }^{* *}=$ Personal communication, Sanchez, Centers for Disease Control. Yes = TaqMan assay; No= Conventional RT-PCR assay. L=RNA-dependent RNA polymerase; NP= Nucleoprotein gene; GP=Glycoprotein gene.

purification, supernatant was clarified in a Sorvall centrifuge at $8000 \mathrm{rpm}$ in a GSA rotor. Seven percent (w/v) PEG (average MW 6000) and 2.3\% (w/v) NaCl was added to supernatant. The virus was allowed to precipitate for $3 \mathrm{~h}$ at $4{ }^{\circ} \mathrm{C}$. The precipitate was then purified through a discontinuous $10-40 \%$ renograffin gradient (Bracco Diagnostics Inc., Princeton, NJ, USA) in a SW-41 rotor at $37000 \mathrm{rpm}$ for $75 \mathrm{~min}$. The visible virus band was harvested and diluted in TNE. The diluted virus was then purified though a continuous $10-50 \%$ renograffin gradient at $30000 \mathrm{rpm}$ overnight. The virus was harvested, pelleted by centrifugation in a SW41 rotor at $38000 \mathrm{rpm}$ for $45 \mathrm{~min}$ and suspended in $2 \mathrm{ml}$ of TNE (Jahrling, unpublished protocol). For VSV purification, cell culture supernatants were clarified by centrifugation at $10000 \times \boldsymbol{g}$ for 30 min. PEG (avg. MW 8000) and $\mathrm{NaCl}$ were added to clarified supernatant to 7 and $2 \cdot 3 \%$ respectively. Virus was precipitated overnight at $4{ }^{\circ} \mathrm{C}$. Precipitated virus was then pelleted by centrifugation at $10000 \times \mathbf{g}$ for $30 \mathrm{~min}$, resuspended in Dulbecco's phosphatebuffered saline (PBS), and then purified by centrifugation through a $20-60 \%(\mathrm{w} / \mathrm{w})$ sucrose density gradient for $3.5 \mathrm{~h}$ at $100000 \times \mathbf{g}$. Sucrose solutions were prepared in Hank's balanced salt solution (HBSS) without $\mathrm{NaHCO}_{3}$ containing 0.02 MN-2-hydroxyethylpiperazine- $N^{\prime}$-2-ethanesulfonic acid (HEPES) buffer $(\mathrm{pH} 7 \cdot 2){ }^{16}$

Filoviruses were titred by performing plaque assays on Vero E6 cells as described previously. ${ }^{17}$ Viral stock was serially diluted in minimum essential medium with Earle salts (EMEM) containing non-essential amino acids (NEAA), adsorbed onto confluent Vero E6 cells in 12 -well dishes, incubated for $1 \mathrm{~h}$ at $37^{\circ} \mathrm{C}$, and covered with an agarose overlay. A 1:5000 dilution of neutral red in buffered saline solution was added 7 days later, and plaques were counted the following day.

\section{Primer and probe design}

The characteristics of selected primer and probe sets are listed in Table 1. Sequences of the Musoke, Ravn, and Popp strains of Marburg were aligned by using the DNA Star MegAlign software. After careful study of the aligned sequences, a highly conserved region of the GP gene was targeted for primer/probe development. A primer/probe set, designated MBGGP3, was designed by evaluating the Marburg virus glycoprotein gene [GenBank Accession Nos, Z29337 (Marburg, Popp strain); Z12132 (Marburg, Musoke strain); and AF005734 (Marburg, Ravn strain)] using Primer Express Software ${ }^{\mathrm{TM}}$ (Applied Biosystems). The primer and probe set was designed to meet the guidelines recommended by Applied Biosystems. In brief, the primers were designed with melting temperatures $\left(T_{m}\right)$ between $58-60^{\circ} \mathrm{C}$. Probes were designed to have a $T_{m}$ at least $7-10^{\circ} \mathrm{C}$ higher than the primer $T_{m}$. The presence of a guanine at the $5^{\prime}$ end of probes was avoided and the amplicons were designed to be less than $200 \mathrm{bp}$ in length. Primer and probe dimers, hairpins, stem-loops, and false-priming sites were minimized. The sequences of the primers are: MBGGP3 forward primer: 5'-TTCCCCTTTGGAGGCATC-3'; and MBGGP3 reverse primer: 5'-GGAGGATCCAACAGCAAGG-3'. The probe sequence is: MBGGP3Prb 5'-CGATGGGCTTTCAGGACAGGTGT-3'.

\section{Fluorogenic $5^{\prime}$-nuclease assays}

RT-PCRs were performed on an ABI PRISM ${ }^{\mathrm{TM}} 7700$ Sequence Detection System (Applied Biosystems) using Applied Biosystems TaqMan ${ }^{\circledR}$ EZ RT-PCR kit in accordance with the manufacturer's instructions. Final concentrations used in the $50 \mu$ reaction mix were: $0.5 \mu \mathrm{M}$ of each primer, $0.2 \mu \mathrm{M}$ of probe, $5 U$ $\mathrm{rTth}$ enzyme, $300 \mu \mathrm{M}$ deoxynucleotide triphosphates, $1 \times$ Applied Biosystems TaqMan ${ }^{\circledR}$ RT-PCR buffer containing the passive reference dye ROX, and $2.5 \mathrm{mM}$ manganese acetate. Thermocycling conditions for the MBGGP3 primer/probe set were as follows: $55^{\circ} \mathrm{C}$ for $45 \mathrm{~min}, 94^{\circ} \mathrm{C}$ for $1 \mathrm{~min}$, followed by 40 cycles at $94^{\circ} \mathrm{C}$ for $15 \mathrm{~s}$, and $60^{\circ} \mathrm{C}$ for $30 \mathrm{~s}$. Total assay time on the ABI PRISM ${ }^{\mathrm{TM}} 7700$ Sequence Detection System was approximately $2 \mathrm{~h}$. 


\section{Conventional RT-PCR assays}

Previously published primer sets (Table 1 ) were tested using the Applied Biosystems EZ rTth RNA PCR kit (Applied Biosystems) according to the manufacturer's instructions. Thermocycling conditions for each set were published previously. ${ }^{9}$ Final concentrations used in the $50 \mu \mathrm{l}$ reaction mix were: $0 \cdot 5 \mu \mathrm{M}$ of each primer, $5 U$ rTth enzyme, $300 \mu \mathrm{M}$ deoxynucleotide triphosphates, $1 \times$ Applied Biosystems EZ buffer, and $2.5 \mathrm{mM}$ manganese acetate. All assays were performed on a PTC 100 thermocycler (MJ Research, Waltham, MA, USA).

\section{Sequencing of RT-PCR products}

To verify identity of PCR products, we sequenced amplicons from RT-PCR reactions using dye-labelled terminators and cycle sequencing (Taq Prism kit, Applied Biosystems). Products from sequencing reactions were analysed on an $\mathrm{ABI} 377$ sequencer (Applied Biosystems). The sequences were then identified using the National Center for Biotechnology Information's Basic Local Alignment Search Tool (BLAST) (Internet web address: http:// www.ncbi.nlm.nih.gov/BLAST/).

\section{Limit of detection (LOD) assays}

To determine plaque-forming unit (pfu) LODs, serial 10-fold dilutions of sucrose-purified Marburg virus stocks (Musoke strain and Ravn strain) were prepared in $1 \mathrm{ml}$ of EMEM/NEAA. No sample controls were prepared using virus free EMEM/NEAA. One hundred microliters of each dilution were placed in Trizol LS (Gibco BRL, Gaithersburg, MD, USA), and RNA isolation was performed in accordance with the manufacturer's instructions. Briefly, chloroform was added to the virus/Trizol LS mixture and following centrifugation the aqueous phase containing the RNA was harvested. RNA was then precipitated with the addition of isopropanol, washed with $75 \%$ ethanol, and resuspended in $100 \mu \mathrm{l}$ of RNase free water. One microliter of each RNA preparation was used in subsequent $\operatorname{TaqMan}^{\circledR}$ and conventional RT-PCR assays. TaqMan ${ }^{\circledR}$ assays were performed in triplicate. In order to quantify the virus titre of the purified virus preparations, serial 10 -fold dilutions were plaqued on Vero E6 cells as previously described (see above). The LOD was defined as the last dilution in the fluorogenic $5^{\prime}$-nuclease assays in which the $C_{T}$ value (threshold cycle) was less than 40.

To determine the LODs of purified viral RNA, sucrose purified virus was placed in Trizol LS (Gibco $\mathrm{BRL}$ ), and RNA isolation was performed in accordance with the manufacturer's instructions. Briefly, chloroform was added to the virus/Trizol LS mixture, centrifuged, and the aqueous phase containing the RNA was harvested. Viral RNA was then precipitated with the addition of isopropanol, washed with $75 \%$ ethanol, and resuspended in RNase free water. The RNA was quantitated by spectrophotometry and serial 10fold dilutions were prepared from $1 \mathrm{ng}$ to $10 \mathrm{fg} \mu \mathrm{I}^{-1}$. One microliter of each dilution was used in subsequent $\operatorname{TaqMan}^{\circledR}$ and conventional RT-PCR assays. The LODs of the newly designed TaqMan ${ }^{\circledR}$ assay were compared to the LODs of previously designed Marburg primers (Table 2). ${ }^{9}$

\section{Blind tissue panel}

Spleen, brain, lung, liver, and kidney were collected from non-human primates that died following a challenge with Marburg virus (Ravn strain). All tissues were shown to be positive for Marburg virus in subsequent plaque assays (Hevey, personal communication). In parallel, control tissues were collected from healthy non-human primates obtained commercially (BioWhittaker, Walkersville, MD, USA). Tissues were snap frozen in liquid nitrogen and stored at $-70^{\circ} \mathrm{C}$ until processing. For RNA extraction, tissues were weighed, placed in the appropriate amount $(1 \mathrm{ml}$ per $100 \mathrm{mg}$ of tissue) of Trizol (Gibco BRL), and homogenized. The RNA was extracted as described above. Five microliters of each $100 \mu$ l RNA preparation was used in subsequent TaqMan ${ }^{\circledR}$ assays. The study was blinded by an independent investigator who assigned random numbers to each sample.

\section{Cross-reactivity panel}

To evaluate the cross-reactivity of the MBGGP3 primer/probe set, RNA from genetically related viruses [vesicular stomatitis virus, measles virus, Ebola virus (Zaire, Sudan, Ivory Coast, Reston strains)] and other haemorrhagic fever viruses (Lassa virus and CrimeanCongo haemorrhagic fever virus) was isolated. The RNA from these viruses was extracted from purified viral seeds with Trizol LS as described previously. One nanogram of each viral template was used for cross-reactivity tests. The cross-reactivity panel was blinded by an independent investigator who assigned random numbers to each sample. 
Table 2. Sensitivity of Marburg virus primer/probe sets

\begin{tabular}{lcccccc}
\hline Primer Set & \multicolumn{2}{c}{$\begin{array}{c}\text { Musoke Limit of detection } \\
\text { (LOD) }\end{array}$} & & & \multicolumn{2}{c}{ RAVN-LOD } \\
\cline { 2 - 3 } \cline { 6 - 7 } & pfu & Mass & & pfu & Mass \\
\hline REM2/REM3* & $5 \mathrm{pfu}$ & $10 \mathrm{pg}$ & & & $300 \mathrm{pfu}$ & $1 \mathrm{ng}$ \\
FILOA/FILOB* & $80 \mathrm{pfu}$ & $10 \mathrm{pg}$ & & \multicolumn{2}{c}{ Not detected } \\
MBGGP3 & $5 \mathrm{pfu}$ & $1 \mathrm{pg}$ & & & $2 \mathrm{pfu}$ & $10 \mathrm{pg}$ \\
\hline
\end{tabular}

Key: * Previously designed primer sets. pfu $=$ plaque forming units. PFU LODs are based on a known number of plaque forming units from which viral RNA was extracted. Mass LODs are based on a known amount of purified viral RNA.

\section{Direct analysis and detection of RT-PCR- amplified products on agarose gels}

Ten $\mu \mathrm{l}$ aliquots of the RT-PCR products were electrophoresed on $4 \%$ agarose gels (FMC BioProducts, Rockland, ME, USA) in Tris-borate buffer (TBE) containing $1 \mu \mathrm{g}$ per $\mathrm{ml}$ ethidium bromide. DNA bands were visualized with an Alpha-Inotech imaging system (Alpha Inotech Corporation, San Leandro, CA, USA).

\section{RESULTS}

\section{TaqMan $^{\circledast}$ primer/probe design}

Two hundred possible sets of primers and probes specific for one of the highly conserved regions of the Marburg GP gene were generated using the Primer Express $^{\mathrm{TM}}$ software. The MBGGP3 primer/probe set was chosen based on guidelines recommended by PE Applied Biosystems, as outlined previously in the materials and methods. The primer/probe set chosen, MBGGP3, was designed to amplify a 143 bp region of the GP gene.

\section{Limit of detection experiments}

The MBGGP3 primer/probe set limit of detection was equivalent to or 10-100 times greater than previously designed primer sets intended for use in conventional RT-PCR assays (Table 2). The MBGGP3 primer/probe set was able to detect $1 \mathrm{pg}$ of purified Marburg (Musoke strain) RNA and 5 pfu of infectious virus (Table
2 and Fig. 1a). MBGGP3 was also able to detect 10 pg of purified Marburg (Ravn strain) RNA and 2 pfu infectious virus (Table 2 and Fig. 1b). Previously designed primer sets (REM2/REM3 and FILOA/FILOB) for use in conventional RT-PCR assays were able to detect $10 \mathrm{pg}$ and $5 \mathrm{pfu}$ (REM2/REM3) or $10 \mathrm{pg}$ and $80 \mathrm{pfu}$ (FILOA/FILOB) of purified Marburg (Musoke strain) RNA or infectious virus, respectively. REM2/ REM3 was able to detect 1 ng of Marburg (Ravn strain) RNA and 300 pfu infectious virus. The FILOA/FILOB primer set was not able to detect Marburg virus (Ravn strain) (Table 2). All no sample controls were negative. TaqMan $^{\circledR}$ results were confirmed by observing the expected band size on $4 \%$ agarose gels.

\section{Cross-reactivity experiments}

Several genetically related viruses and other haemorrhagic fever viruses were used to determine the cross-reactivity of the MBGGP3 primer/probe set. The MBGGP3 primer/probe set detected both strains of Marburg virus tested (Musoke and Ravn) but did not detect any of the genetically related or other haemorrhagic fever viruses (Table 3). Although REM2/ REM3 detected both the Musoke and Ravn strains of Marburg virus, it also amplified Ebola Zaire. The FILOA/FILOB primer set was able to detect Marburg virus (Musoke strain), however, it also amplified Ebola viruses [Zaire, Sudan, and Ivory Coast (IC) strains]. The amplicon observed with FILOA/FILOB and $1 \mathrm{ng}$ of Ebola IC template was very faint. Therefore, neither of the previously designed primer sets (REM2/REM3 or FILOA/FILOB) was specific for Marburg virus (Table 3). TaqMan ${ }^{\circledast}$ results were confirmed by observing the expected band size on $4 \%$ agarose gels. 

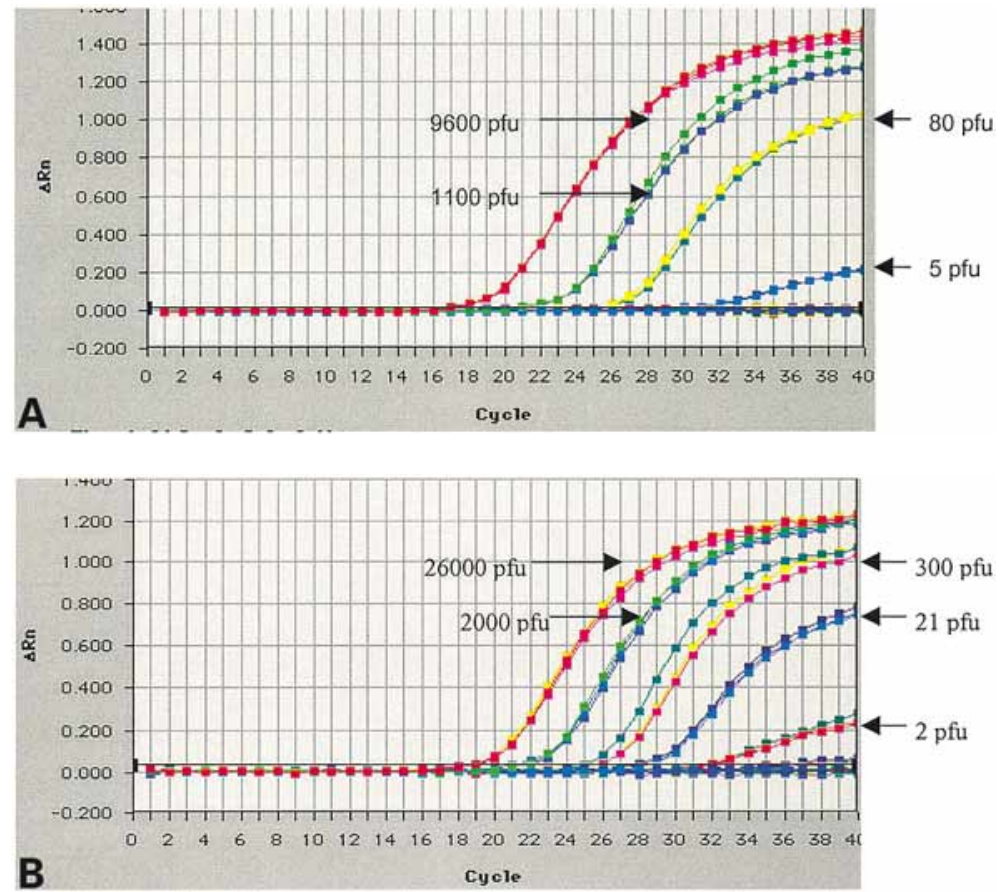

Fig. 1. Sensitivity of MBGGP3 TaqMan ${ }^{\circledR}$ Assay for (a) Marburg virus (Musoke strain) and (b) Marburg virus (Ravn strain). Total RNA isolated from serial dilutions of sucrose-purified virus was used as the template. Each sample was run in triplicate. The graphs depict amplification plots for both templates.

Table 3. Cross reactivity panel: Marburg virus primer sets

\begin{tabular}{|c|c|c|c|c|c|c|c|c|c|c|}
\hline Primer Set & Lassa & Measles & VSV & $\mathrm{CCHF}$ & Ebo-Z & Ebo-S & Ebo-IC & Ebo-R & MBG-RAVN & MBG-MSK \\
\hline MBGGP3 & - & - & - & - & - & - & - & - & + & + \\
\hline REM2/REM3* & ND & ND & ND & ND & + & - & - & - & + & + \\
\hline FILOA/FILOB* & ND & ND & ND & ND & + & + & + & - & - & + \\
\hline
\end{tabular}

Key: * Previously designed primer sets. VSV (vesicular stomatitis virus); CCHF (Crimean-Congo haemorrhagic fever virus); Ebo-Z (Ebola-Zaire); Ebo-S (Ebola-Sudan); Ebo-IC (Ebola-Ivory Coast); Ebo-R (Ebola-Reston); MBG-RAVN (Marburg Ravn); MBG-MSK (Marburg Musoke). $+=$ amplicon detected, $-=$ no amplicon detected, ND= No data.

\section{Detection of Marburg Ravn from infected cynomolgus monkeys}

Specificity of the MBGGP3 primer/probe set was tested in a blinded fashion with RNA isolated from 20 control tissues and 10 tissues harvested from nonhuman primates infected with Marburg virus (Ravn strain). The clinical specificity of MBGGP3 primer/ probe set was $100 \%$ (Table 4). Fluorogenic 5'-nuclease assays performed with viral RNA from infected tissues produced $C_{T}$ values of $<40$, indicating the sample was positive for Marburg virus, and also resulted in the expected $143 \mathrm{bp}$ amplicon when observed by gel electrophoresis. In contrast, control samples did not cross threshold during the 40 cycles of the PCR assay (indicating an absence of Marburg virus) and no amplicons were observed by gel electrophoresis in these samples.
Table 4. Blind tissue panel: Marburg Ravn infected nonhuman primates

\begin{tabular}{cccc}
\hline $\begin{array}{c}\text { True } \\
\text { positives }\end{array}$ & $\begin{array}{c}\text { False } \\
\text { positives }\end{array}$ & $\begin{array}{c}\text { True } \\
\text { negatives }\end{array}$ & $\begin{array}{c}\text { False } \\
\text { negatives }\end{array}$ \\
\hline 10 & 0 & 20 & 0
\end{tabular}

Specificity of MBGGP3 primer-probe set tested in a blind tissue study. A blind tissue study was performed with tissues obtained from a live non-human primate challenge with Marburg virus (Ravn strain). Specificity of the newly designed primer/probe set was determined in a TaqMan ${ }^{\circledR}$ assay. Uninfected non-human primate tissues served as controls. $(n=30)$

\section{DISCUSSION AND CONCLUSIONS}

This report describes the development and evaluation of a one-tube fluorogenic RT-PCR assay on the ABI PRISM $^{\text {TM }} 7700$ Sequence Detection System for the 
identification of Marburg virus infections. The GP gene of Marburg virus was chosen as an assay target for several reasons. First, the GP protein of Marburg and Ebola viruses is required for virus entry into cells. Second, the membrane-bound GP of Ebola virus is reported to play a central role in the virus-mediated cytotoxicity of endothelial cells and therefore appears to be an important virulence factor of the Ebola virus. ${ }^{18}$ Finally, the GP gene of all Marburg virus strains contains highly conserved regions that permitted the design of primer/probe sets based on the guidelines set forth by Applied Biosystems.

This assay has several advantages over conventional RT-PCR assays that are currently used for the identification of Marburg virus. The LOD of this assay was equivalent to or 10-100-fold greater than that of previously designed primer sets (Table 2). REM2/REM3 was capable of detecting both Marburg virus strains tested (Musoke and Ravn), but only at a limit of $10 \mathrm{pg}$ and $1 \mathrm{ng}$, respectively. FILOA/FILOB was only capable of amplifying the Musoke strain. Based on LOD assays, the MBGGP3 primer/probe set was capable of detecting 1 pg of Marburg virus (Musoke strain) and $10 \mathrm{pg}$ of Marburg virus (Ravn strain) purified nucleic acids (Table 2). In order to express the limit of detection of MBGGP3 primer/ probe set as a more clinically relevant number, LOD assays were performed on serial dilutions of purified virus containing a known amount of pfu. The MBGGP3 primer/probe set was capable of detecting 5 pfu of Marburg virus (Musoke strain) and 2 pfu of Marburg virus (Ravn strain). The discrepancy between the pfu LODs and the mass LODs (expressed as the total amount of viral RNA added to assay) can be explained by the method by which each assay was performed and quantitated. The mass LOD assays were performed by preparing serial 10-fold dilutions of an initial stock of RNA that was quantitated by spectrophotometry. The LOD assays expressed in total pfu were performed by serially diluting sucrose-purified viral stocks and then determining the titres of each dilution. Therefore, with the plaque assay method for determining LOD, the number of pfu were determined after the dilutions were prepared. With the mass LOD method, the amount of RNA in each dilution was not determined subsequent to dilutions being prepared. Therefore, it is likely that the LODs expressed in pfu are in fact more accurate than the LOD assays performed with total RNA alone (mass LODs).

The MBGGP3 assay was highly specific for Marburg virus. Other primer sets used in conventional RT-PCR assays did not show the same level of specificity. The MBGGP3 primer/probe set was specific for all Marburg strains tested in a blinded cross-reactivity panel and showed an estimated clinical specificity of
$100 \%$ when tested against a blind tissue panel (Table 4). The blinded tissue panel contained tissues from non-human primates challenged with Marburg virus (Ravn strain). In contrast, previously designed primer/ probe sets amplified one (REM2/REM3) or more (FILOA/FILOB) subtypes of Ebola virus and therefore lacked the specificity of the MBGGP3 primer/probe set (Table 3).

The one-tube fluorogenic RT-PCR assay is compatible with emerging rapid nucleic-acid analysis platforms. ${ }^{19}$ These new platforms are capable of performing both thermocycling and fluorescence detection in real time. Sources of these instruments include Applied Biosystems, Roche Diagnostics (Indianapolis, IN, USA), Idaho Technologies (Salt Lake City, UT, USA), Cepheid (Sunnyvale, CA, USA) and Bio-Rad (Hercules, CA, USA). With the more rapid thermocycling instruments, [Lightcycler ${ }^{\mathrm{TM}}$ (Roche Molecular Systems), the ruggedized Advanced Pathogen Identification Device (R.A.P.I.D. ${ }^{\mathrm{TM}}$, Idaho Technologies) or the SmartCycler ${ }^{\mathrm{TM}}$ (Cepheid)], it is reasonable to assume that once a sample is received and processed, a definitive diagnosis can be made within 20-40 min. ${ }^{20}$ In addition, the use of this technology in field laboratories has become a reality with availability of instruments such as the R.A.P.I.D. ${ }^{\mathrm{TM}}$ and SmartCycler $\mathrm{XC}^{\mathrm{TM}}$, which have been specifically designed for use by field medical laboratories.

To obtain an early diagnosis and contain future outbreaks of Marburg haemorrhagic fever, it will be necessary to implement a rapid diagnostic assay in laboratories throughout Africa. This assay must not require great levels of technical skill to perform and must be accurate and reproducible. Transfer of the newly designed fluorogenic 5' nuclease assay described in this study to rapid nucleic-acid analysis platforms would be a first step towards providing public health authorities in Africa with a tool to help diagnose and contain possible outbreaks. Future developments producing a dried-down chemistry for RT-PCR (making the addition of water and sample the only reagents needed for performing the fluorogenic RT-PCR assay) would make this assay more easy to use in the field and provide a valuable diagnostic capability that would enhance future outbreak investigations.

\section{ACKNOWLEDGEMENTS}

The authors thank Deanna Bridge, Bill Hurtle, Steven Kerby, and Brian Kearney for their excellent technical assistance. We thank Dr Mike Hevey for providing nonhuman primate tissues used in the blind tissue panel. We also thank Dr David Shoemaker and Dr George Ludwig 
for their helpful suggestions and critical input in the preparation of this manuscript. We are especially indebted to Dr George Ludwig for providing Lassa virus, CCHF virus, measles virus, and VSV virus seeds for growth and purification.

This research and development was supported by core support from the U.S. Army Medical Research and Material Command, Fort Detrick, MD 21702. Research was conducted in compliance with the Animal Welfare Act and other Federal statutes and regulations relating to animals and experiments involving animals and adheres to principles stated in the Guide for the Care and Use of Laboratory Animals, National Research Council, 1996. The facility where this research was conducted is fully accredited by the Association for Assessment and Accreditation of Laboratory Animal Care International.

\section{REFERENCES}

1. Anon. (1978). Ebola haemorrhagic fever in Zaire, 1976. Bulletin of the World Health Organization 56, 271-93.

2. Anon. (1978). Ebola haemorrhagic fever in Sudan, 1976. Report of a WHO/International Study Team. Bulletin of the World Health Organization 56, 247-70.

3. Anon. (1995). From the Centers for Disease Control and Prevention. Update: management of patients with suspected viral haemorrhagic fever-United States. Journal of the American Medical Association 274, 374-5.

4. Khan, A. S., Tshioko, F. K., Heymann, D. L., Le Guenno, B., Nabeth, P., Kerstiens, B., Fleerackers, Y., Kilmarx, P. H., Rodier, G. R., Nkuku, O., Rollin, P. E., Sanchez, A., Zaki, S. R., Swanepoel, R., Tomori, O., Nichol, S. T., Peters, C. J., Muyembe-Tamfum, J. J., \& Ksiazek, T. G. (1999). The reemergence of Ebola haemorrhagic fever, Democratic Republic of the Congo, 1995. Commission de Lutte contre les Epidemies a Kikwit. Journal of Infectious Diseases $\mathbf{1 7 9}$ Suppl 1, S76-86.

5. Peters, C. J., Sanchez, A., Rollin, P. E., Ksiazek, T. G., \& Murphy, F. A. (1996). Filoviridae: Marburg and Ebola viruses. In Fields Virology (B. N.Fields, D. M.Knipe, P. M.Howley, et al., eds) Third ed. (1), Pp. 1161-76. Philadelphia: Lippincott-Raven Press.

6. Geisbert, T. W. \& Jahrling, P. B. (1995). Differentiation of filoviruses by electron microscopy. Virus Research 39, 129-50

7. Baize, S., Leroy, E. M., Georges-Courbot, M. C., Capron, M., Lansoud-Soukate, J., Debre, P., Fisher-Hoch, S. P., McCormick, J. B., \& Georges, A. J. (1999). Defective humoral responses and extensive intravascular apoptosis are associated with fatal outcome in Ebola virus-infected patients [see comments]. Nature Medicine 5, 423-6.

8. Leroy, E. M., Baize, S., Volchkov, V. E., Fisher-Hoch, S. P., Georges-Courbot, M. C., Lansoud-Soukate, J.,
Capron, M., Debre, P., McCormick, J. B., \& Georges, A. J. (2000). Human asymptomatic Ebola infection and strong inflammatory response [see comments]. Lancet 355, 2210-5.

9. Sanchez, A., Ksiazek, T. G., Rollin, P. E., Miranda, M. E., Trappier, S. G., Khan, A. S., Peters, C. J., \& Nichol, S. T. (1999). Detection and molecular characterization of Ebola viruses causing disease in human and nonhuman primates. Journal of Infectious Diseases 179 (Suppl 1), S164-9.

10. Higgins, J. A., Ibrahim, M. S., Knauert, F. K., Ludwig, G. V., Kijek, T. M., Ezzell, J. W., Courtney, B. C., \& Henchal, E. A. (1999). Sensitive and rapid identification of biological threat agents. Annals of the New York Academy of Sciences 894, 130-48.

11. Holland, P. M., Abramson, R. D., Watson, R., \& Gelfand, D. H. (1991). Detection of specific polymerase chain reaction product by utilizing the $5^{\prime}-3^{\prime}$ exonuclease activity of Thermus aquaticus DNA polymerase. Proceedings of the National Academy of Sciences, U.S.A 88, 7276-80.

12. Bassler, H. A., Flood, S. J., Livak, K. J., Marmaro, J., Knorr, R., \& Batt, C. A. (1995). Use of a fluorogenic probe in a PCR-based assay for the detection of Listeria monocytogenes. Applied and Environmental Microbiology 61, 3724-8.

13. Eun, A. J., Seoh, M., \& Wong, S. (2000). Simultaneous quantitation of two orchid viruses by the TaqMan real-time RT-PCR. Journal of Virological Methods 87, 151-60.

14. Hevey, M., Negley, D., Geisbert, J., Jahrling, P., \& Schmaljohn, A. (1997). Antigenicity and vaccine potential of Marburg virus glycoprotein expressed by baculovirus recombinants. Virology 239, 206-16.

15. Hodgsen, L. The sequence, genomic organization, and expression of the small genomic segment of Crimean Congo haemorrhagic fever virus for the potential use as a diagnostic antigen. 29-30. 1992. Hood College.

16. Ludwig, G. V., Kondig, J. P., \& Smith, J. F. (1996). A putative receptor for Venezuelan equine encephalitis virus from mosquito cells. Journal of Virology $\mathbf{7 0 ,}$ 5592-9.

17. Moe, J. B., Lambert, R. D., \& Lupton, H. W. (1981). Plaque assay for Ebola virus. Journal of Clinical Microbiology 13, 791-3.

18. Yang, Z. Y., Duckers, H. J., Sullivan, N. J., Sanchez, A., Nabel, E. G., \& Nabel, G. J. (2000). Identification of the Ebola virus glycoprotein as the main viral determinant of vascular cell cytotoxicity and injury. Nature Medicine 6, 886-9.

19. Espy, M. J., Uhl, J. R., Mitchell, P. S., Thorvilson, J. N., Svien, K. A., Wold, A. D., \& Smith, T. F. (2000). Diagnosis of herpes simplex virus infections in the clinical laboratory by LightCycler PCR. Journal of Clinical Microbiology 38, 795-9.

20. Belgrader, P., Benett, W., Hadley, D., Long, G., Mariella, R., Milanovich, S., Nasarabadi, W. N., Richards, J., \& Stratton, P. (1998). Rapid pathogen detection using a microchip PCR array instrument. Clinical Chemistry 44, 2191-94. 